\title{
Creating an Organizationally Embedded Strategic Communication Plan for Libraries \\ Doralyn Rossmann
}

\section{Abstract}

This is the first in a series of articles appearing in Library Leadership \& Management that provides library leaders with an outline for creating a sustainable and consistent communication plan across all platforms and venues. Going beyond traditional marketing and branding, this series suggests a comprehensive approach to communication - both to people and to the computer networks that people use - for everyday communication, for disaster planning, and for the library's strategic endeavors. There are many elements that can communicate and convey a library's identity and values - social media posts, budget structures, library guides, strategic plans, etc. A coordinated and strategic plan for communication and outreach will strengthen your library's value by creating a common experience and understanding by your library community, including library patrons, boards, administrators, and donors as well as internet search engines, social media networks, and their users. This plan will keep the library focused on objectives from the strategic plan and not straying beyond the plan, which could otherwise drain resources from what is trying to be achieved. This first article outlines the purpose and development of a library's values, mission, and vision statements, a strategic plan, a communication plan, and the embedding of that plan in organizational culture. Subsequent articles explore offshoots of this communication including budgeting message and presentation, social media strategies, and search engine optimization and semantic web identity.

\section{Introduction}

Effective, intentional communication about library values, aspirations, goals, and plans is essential to keeping library efforts within scope, building library support, creating a justifiable budget, and being prepared for unexpected crises. Many libraries expend numerous resources developing values, mission, and vision statements which, in turn, inform strategic plans. These statements and plans can be quickly forgotten if not intentionally integrated into daily communication workflow. If library employees are not fully informed about their library, how can the library expect members of their community to understand the organization? For example, do library employees understand the structure of the library's budget, the strategies used in managing the library's social media accounts, the representation of the library through search engines like Google and Bing, and the existence of a strategic plan? Consider that a lack of common knowledge of the library by its employees may lead to inconsistent communication resulting in user frustration, confusion over what the library is trying to achieve, and, ultimately, reduced value placed in the library and reduced support for the budget to support its efforts. This inconsistent communication and lack of understanding by its employees and community undermines the library's mission, value, plans, and its potential as a force for community good. Conversely, a library with a thoughtfully constructed, consistently followed, communication plan can create a strong, unified, and commonly understood direction for the library, its users, and its supporters. 
This is the first in a series of articles appearing in Library Leadership \& Management that provides library leaders with an outline for creating a sustainable and consistent communication plan across all platforms and venues. Going beyond traditional marketing and branding, this series suggests a comprehensive approach to communication - both to people and to the computer networks that people use for everyday communication, for disaster planning, and for the library's strategic endeavors. There are many elements that can communicate and convey a library's identity and values - social media posts, budget structures, library guides, strategic plans, etc. A coordinated and strategic plan for communication and outreach will strengthen your library's value by creating a common experience and understanding by your library community, including library patrons, boards, administrators, and donors as well as internet search engines, social media networks, and their users. This plan will keep the library focused on objectives from the strategic plan and not straying beyond the plan, which could otherwise drain resources from what is trying to be achieved. This first article outlines the purpose and development of a library's values, mission, and vision statements, a strategic plan, a communication plan, and the embedding of that plan in organizational culture. Subsequent articles explore offshoots of this communication including budgeting message and presentation, social media strategies, and search engine optimization and semantic web identity.

\section{Literature Review}

To establish common language, direction, and goals, building a communication plan begins with the creation of a values statement, mission statement, vision statement, and strategic plan (for the purposes of this discussion, the "Statements" - values statement, mission statement, vision statement and "Plans" - strategic plan, and communication plan -come together into "Statements and Plans" and is abbreviated to "S\&P"). With the S\&P in place, you can establish how you will conduct routine communications as well as strategic communications derived from your strategic plan. As Kuchi observes "In order to be proactive and foresee change, libraries have to be strategic in their approach (Pugh, 2000). Such a path needs to be supported by a library's structural and cultural orientation for planning and communicating, especially to the internal as well as external stakeholders. Communicating a library's strategic plan and directions will instill stronger confidence in its constituencies about its programs, decisions and activities, as well as about the library's sustainability and capability for handling chaos in its environment." Consequently, the library's budget and resources allocations will be better understood and justifiable.

While the values, mission, and vision statements and strategic plan are all commonly used elements in library management culture, forming a communication plan is less prevalent in the profession. Libraries may invest time and effort into communication plans around a specific activity or resource, but these can be limited in scope and intention. Kuchi notes: "A library's communication plans typically comprise a layout of steps to inform all concerned about its products and services...and are largely created for specific purposes of publicizing or marketing the new product or activity. Such communication plans typically tend to be ad-hoc and reactive. Although useful, they are fragmentary and do not present a coherent picture of a library's strategic direction or path for handling changes in the environment." Why is a comprehensive and strategic communication plan important? "Communication helps libraries gain stakeholder support as well as reduce the library's struggle to manage conflicts and change." It also keeps everyone in the library organization and stakeholders on the same page of what the library is trying to achieve with its allocated resources. It explains where your time and efforts are going and why. This series of articles outlines approaches to more commonly found elements in communication strategic plans such as web messaging and outreach and social media activity as well as the elements less commonly found such as semantic web identity, search engine 
optimization, social media optimization, and budget presentation. These approaches can be made more focused and consistent by using the language and goals that are from the various parts of the S\&P.

\section{Creating Statements and Plans (S\&P)}

\section{Objective: To create a library values statement, mission statement, vision statement, and} strategic plan to focus library efforts and use of allocated resources.

Before embarking on creating a communication plan, it can be useful to use existing documents or create new ones to shape the language used on the plan. Many libraries focus their efforts by formalizing their intentions through a values statement, a mission statement, a vision statement, and a strategic plan (parts of the S\&P) which can be used form the foundation for the library's communication plan (Figure 1).

\section{The 5 Parts of the S\&P (Statements and Plans)

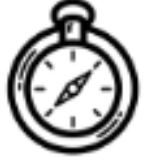 \\ Values \\ Statement

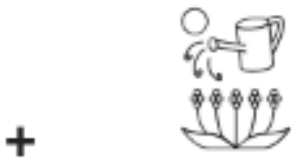 \\ Strategic \\ Plan

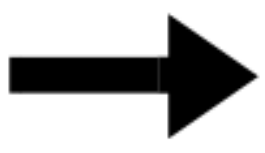 \\ Communication \\ Plan}

Figure 1: The 5 Parts of the S\&P (Statements and Plans) ${ }^{1}$

Some libraries may only have some parts of the S\&P in place. Other libraries may have these ideas as an informal part of their culture, but may not have put them in writing for internal or external audiences. While not all of these parts are required to write a communication plan, establishing at least one of the statements and a few strategic directions can provide members of the organization with commonly understood language about why the library does what it does - and does not do what it does not do. If you already have up-to-date elements of the S\&P in place, you may want to jump to the next section which outlines the formation of the communication plan, the final part of the S\&P. With some or all of the parts of the S\&P, the 
library can build a communication plan which focuses these efforts using shared language and commonly understood direction which reflect what the library is and what it is trying to achieve.

There are many resources in the library and business literature which can offer ideas of how to navigate your specific S\&P process, especially the strategic planning step. Miller et. al provide results of an exploratory survey and literature review to explore what was and was not helpful to libraries in their strategic planning processes. ${ }^{2}$ Wayne outlines his academic library's strategic planning and associated vision statement creation process. "3 Nutefall provides a great overview of the S\&P process and discusses the benefits of using an outside facilitator to help guide the process. ${ }^{4}$ One popular tool in libraries is the Balanced Scorecard. De la Mano and Creaser (2014) offer a summary of many of these efforts. Cervone adopts a Scrum model to allow for agile strategic planning. ${ }^{5}$ Dole, Dabbour, and Kott discuss the problems with libraries using business models to go through the S\&P process and, instead, offer an approach to S\&P designed for libraries which uses appreciative inquiry as its foundation. ${ }^{6}$ Saunders surveys existing academic library strategic plans for trends and underrepresented areas. ${ }^{7}$ I recommend using these readings to decide how you approach developing and updating your strategic plan.

Keep in mind that the S\&P process itself is, in many ways, as important as the outcomes of that process. You will want to make sure to give your organization time and space to work through the process so that members of the organization feel ownership for the S\&P created, have a common understanding of the library's priorities and strategies, and be able to use the S\&P to guide their work and future projects that may come their way.

\section{The 5 Parts of the S\&P}

When making your S\&P, it can be useful to create the values statement first, since your values will drive your mission, vision, and strategy. Then, a mission statement and vision statement set a focus on what your library does and how it will get to where it wants to go. The strategic plan then builds on these statements and sets goals, strategies to achieve these goals, and measures of success for the next several years. Finally, the communication plan reflects all that was formed through this process to form clear and consistent messaging. Each of the parts of the S\&P is described in the following section, with the communication plan described in further detail in the subsequent section

\section{Values Statement}

The values of your library and of your organization will inform what is reflected in your mission statement, your vision statement, and the priorities set forth in your strategic plan. The Society for Human Resource Management (SHRM) describes the values statement as "what the organization believes in and how it will behave." 8 In addition to visiting any values statement from your parent organization, it may be useful for your library to review some of values of the library profession such as the American Library Association's (ALA) "Core Values of Librarianship" and the International Federation of Library Associations and Institutions (IFLA) "Core Values" to find language and ideas that may resonate with your employees. ${ }^{9}$

It is important that members of your organization talk collectively about what the main concepts in the values statement mean to them and how those concepts tell the story of the library. Keeping in mind that you want to consistently communicate internally and externally about your library, the language established in your values statement should then permeate into your mission and vision statements and, in turn, your strategic plan. 
As an example, an introduction to your values statement could be:

Values: Our organization supports the core values of both the profession of librarianship and the university. Our values reflect how we carry forward our strategic and operational decisions: we aim to build a more informed, thoughtful, and just world while striving to cultivate an environment that supports the potential for finding joy and meaning in our work.

And, then, one of the values under that umbrella could be: Accountability: We are proud of our role serving the university and the people of our state. We hold ourselves accountable to each other, to the ethics of our profession, and to our statewide supporters.

S\&P Exercise 1 - Make a Values Statement:

Complete your own values statement. This statement should answer:

1. What is a summary of your values?

2. What are the values themselves and what are 1-2 examples of how those might look in application?

\section{Mission Statement and Vision Statement}

Once the values statement has been created, your library can then create its mission and vision statements. It is useful to construct these two statements in coordination with each other as they are interrelated and interdependent. SHRM notes that "A mission statement explains the department's reason for existence. It describes the department, what it does and its overall intention. The mission statement supports the vision and serves to communicate purpose and direction to employees, customers, vendors, and other stakeholders. The mission can change to reflect a department's priorities and methods to accomplish its vision."

SHRM provides the following guidance regarding a vision statement. "A vision statement describes the organization as it would appear in a future successful state. When developing a vision statement, try to answer this question: If the organization were to achieve all of its strategic goals, what would it look like 10 years from now? An effective vision statement is inspirational and aspirational. It creates a mental image of the future state that the organization wishes to achieve. A vision statement should challenge and inspire employees." ${ }^{11}$ Lucas-Alfieri observes that a vision statement "in many aspects is a glimpse into the future." 12

The trick to writing mission and vision statements is to make them concise and memorable, but not dull, which can be difficult, but not impossible. The writing of the mission and vision statements can use the same model as the values statement creation process. One difference, though, is to start by returning to the values statement to remind people of the core identity of the library and the words used to describe its values and then embarking on the brainstorming, grouping like concepts, voting, and writing process as was done to create your values statement.

As an example, a mission statement could be:

We support and advance teaching, learning, and research for the university

S\&P Exercise 2 - Make a Mission Statement: 
Complete your own mission statement. This statement should answer:

1. What does your library do?

2. Who does your library serve?

An example vision statement could be: We are a dynamic, adaptive, and responsive research library. We aspire to build innovative digital and physical spaces where our diverse communities can access and apply information to grow intellectually, build meaningful collaborations, communicate ideas, and envision a better future for the state and beyond. and the people of the state, by providing access to information and knowledge.

S\&P Exercise 3 - Make a Vision Statement:

Complete your own vision statement. This statement should answer:

1. What is the personality of your library?

2. What does your library aspire to be?

3. How to you hope to achieve these aspirational goals?

Strategic Plan

With your library's values, mission, and vision statements in place, you are ready to create or update your strategic plan. At this point, hopefully, you've engaged members of your organization in developing your values, mission, and vision statements. You can continue the momentum of having members of your organization thinking about the future by engaging them in the strategic planning process. Keep in mind that strategic plan is not intended to cover everything your library does. It is meant to focus on a few strategic objectives for the next several years, taking a position on how it will meet those strategies, and identifying relevant means to meet those objectives. For instance, an objective may be to reduce costs for college students to attend school. A strategy would be for the library to provide assistance to all faculty in identifying relevant, high-quality open educational resources (OER). Actions might include creating an OER toolkit for faculty, conducting workshops to help faculty identify OER, or hosting OER on the local institutional repository. Measures could include looking at enrollment, cost of texts in previous semesters, and multiplying the two for a total amount of money saved by students.

Begin your process by establishing what perspectives you want to use in looking at your plans. Examples of perspectives to consider could be financial, user, student, donor, etc. Each perspective should have 2-4 objectives which will help achieve what has been outlined in the perspective. Every objective should have ways to measure progress on achieving that objective.

To illustrate, one perspective with objectives could be:

1. Internal Processes Perspective - We will...

a. Create useful, dynamic, and accessible digital and physical spaces;

b. Collaborate with researchers to produce digital research and scholarship;

c. Expand, diversify, and adapt our collections and services; and

d. Grow an engaged library community through marketing and outreach. 
S\&P Exercise 4 - Establish Strategic Objectives:

Complete your own strategic objectives. These objectives should answer:

1. From what perspective is the objective coming?

2. What are 2-4 ways you will achieve this objective?

Once you have established your objectives, you will want to identify some actions to take to achieve those objectives. Then, you need assign measures for those objectives. These measures may include establishing a baseline of your current situation in order to compare it in the future. For example, if you want library-provided electronic resources to be used by a certain minimum percentage of your student population, then you would need to know that you could get that information and establish the current percentage for future comparison.

Building on the example above, Objective 1.a states "Create useful, dynamic, and accessible digital and physical spaces." This objective could have an strategic action item to "make library group study rooms ADA accessible" and could be measured by using one of the many tools and resources identified by the ALA Association of Specialized and Cooperative Library Agency (ASCLA) on their site which might include, for example, "percentage of group study rooms with screen reader technology installed on computers in rooms."

Together, this objective, strategy, and measurement could be summarized:

Objective: 1.a Create useful, dynamic, and accessible digital and physical spaces.

Strategy: Make library group study rooms ADA accessible

Measure: Percentage of group study rooms with screen reader technology installed on computers in rooms

Description: The ALA Association of Specialized and Cooperative Library Agency provides links to many tools and resources to measure compliance with disability needs, including visual needs: https://www.ascladirect.org/resources/.

Formula: Percentage of group study rooms with screen readers

Frequency: Annually (FY)

Baseline: Audit of number of rooms with screen reader

Target: Increase percentage in $25 \%$ increments, minimum until $100 \%$ is reached (maximum 4 years)

Primary Coordinator(s): Antoine Jones

Secondary Coordinator(s): Sarah Pinkelton

Initiative(s): Create an plan to identify which rooms will be upgraded based on the audit

S\&P Exercise 4 - Establish Strategic Objective Measures:

Complete your own strategic objective measures. These measures should answer:

1. What will you count or assess about the objective?

2. How will gather this information? 
3. What formula will be used?

4. How often will this data be collected and analyzed?

5. What will be the baseline against which to measure?

6. What will be a target measure of success?

7. Who will coordinate the gathering and reporting of this information?

8. What initiatives need to take place to make achievement of this objective possible?

\section{Completing the S\&P: Creating the Communication Plan}

\section{Objective: To create a communication plan that incorporates the existing elements of the library's S\&P and centralizes information about communication.}

Now that you have put the first four elements of the S\&P into place, there is a clear outline of the library's purpose and goals. Next, it can be useful to round out your S\&P by creating a communication plan incorporating these ideas into everyday communications and into related efforts made towards fulfilling your strategic plan. Developing a plan will help focus this work by using consistent language, being consistent on where, when, why, and how your library communicates, and helping you keep what your library does within the scope of its established S\&P.

Consider what larger entity- such as a college, university, corporation, city government, county government, school, etc. your library organization is a part of and what means and approaches this parent organization uses to communicate. Also consider how your community communicates and if there are means being used by your parent organization that you could tap into to make the library more visible. How you develop your communication plan and its various steps should take into account the culture of your parent organization and your community so your approach will align and resonate with those who you are trying to reach. This consideration is crucial, as coordinating with your parent organization and connecting with your community will only work if you have developed communication strategies that recognize the approaches and preferences of these entities.

For example, let's say your strategic plan includes an objective to "improve student study spaces for group learning" and you decide to remodel your library's second floor for this purpose. You decide to get student input on what this remodel might include, including the furniture, the paint colors, locations of electrical outlets, signage, and lighting. Your communication plan would remind you all of the places you might want to share this call for input from students and remind you of the language you might want to use in such a call. If one of your values from your values statement is "transparency and accountability," you could consider using those words in your call for input. If this objective is in support of the strategic plan item "Create useful, dynamic, and accessible digital and physical spaces" then you could communicate that broader plan as a part of why you're doing this upgrade. When the project is completed you also might want to include an update to your library's Wikipedia entry to reflect the update to the 2 nd floor and to convey the wording about "improving physical spaces" as a part of the language used there. Your communication plan will help scope out how you manage this project and other library projects, services, and resources moving forward.

In the following list, you can find some publicly posted communication plans of libraries. In these plans, there are elements such as objectives, strategic goals, promotional strategies, target audiences, messaging, branding, style guides, evaluation measures, etc. Some of these plans are tied directly to the library's S\&P and others reference elements of the S\&P but may not be overt in linking their communication plan to the S\&P. Elements not found in these plans 
include other forms of communication such as communication to machines through search engine optimization, semantic web identity, and social media optimization. Also not present is the role of communication in association with budget presentation and resource allocation. The following section explores how to include the basic building blocks of a communication plan while future articles in this series include non-traditional elements of communication plans such as social media optimization and budget presentation.

\section{Examples of Existing Library Communication Plans}

- Cornell University (New York, USA) Library: https://ac.library.cornell.edu/sites/default/files/communication plan 2017 final.pdf

- University of New England (Sydney, Australia) Library: http://www.une.edu.au/ data/assets/pdf file/0016/10375/lcp2.pdf

- Saskatchewan Libraries: http://slta.ca/+pub/document/Promotion/SLTACommunicationsPlan.docx

- Grand Valley Public (Ontario, Canada) Library: http://www.grandvalley.org/ploicy\%20manuals/MarketingandCommunicationsPlanApril2 013.pdf

- City of Muskego (Wisconsin, USA) Public Library: https://www.cityofmuskego.org/DocumentCenter/View/2251

\section{Constructing the Communication Plan}

Your communication plan guides the efforts of the library in all its areas of communication. Library employees, board members, and volunteers will be referred to this document for guidance on the ways and means of communicating. Once established, it should be revisited several times a year and updated every 3-5 years, in coordination with the updating of your S\&P. The elements below can be adjusted to what best suits your library and its culture.

This section includes the potential parts of the plan. The next section discusses the process of developing the plan and socializing the plan. Remember, you can make a plan but it won't be effective unless people actually follow it in their daily work.

\section{Introduction and Purpose}

Begin your communication plan with an outline of its purpose so that others reading the document understand why to use it. Some potential reasons could include:

- Promote awareness of library's activities at any point of contact with the library.

- Build support for the library's activities and ensure a justifiable and supportable budget.

- Keep the library's S\&P at the forefront of communications to keep on track with S\&P and not stray out of scope.

- Make all employees aware of the S\&P and be able to talk about it at all points of communication. For example: writing a position description should obviously align with the library's goals and values and use language from the S\&P. 
Next, to keep the elements of your S\&P as guiding principles for your communications, the communication plan should include all the parts of the S\&P at the beginning of the document

\section{Audience}

Who is your library trying to reach? You likely have different audiences in mind for different communication topics and venues. It can be useful to list these audiences as primary and secondary, and even tertiary, to keep your efforts in scope. It is extremely important to remember that your audience may not be limited to people as computer networks also understand the library based on the algorithms they use to find information. Some audiences could include: current students, tenure-track faculty, alumni, board members, underrepresented and underserved populations, city officials, news media, search engines, social media networks, parents, people with disabilities, homeless population, etc.

\section{Key Messages \& Stories}

Your key messages will be informed by what you established in the other parts of your S\&P. These messages should say what the library is, what it has, what it does, and why. For instance, a key message could be "The Library has useful, dynamic, and accessible digital and physical spaces to support student learning." Ideally, it is best to keep the number of key messages at ten or fewer so as to keep focused and consistent in messaging. If you decide to break out your key messages by audience type, you may have more than ten strategies in total, which is fine.

For each of your key messages, begin to collect stories which convey these messages. Consider what kinds of stories might resonate most with your audience. For example, if the library helped faculty adopt OERs into a class, would any students from that class be willing to share their stories of what that cost savings meant to them in their daily lives?

\section{Communication Venues}

Identify all of the areas where the library communicates and any associated best practices and associated permissions for posting in these venues. This information will let others know what is required to use these venues for communication.

- Website

- Print publications - flyers, brochures, posters

- Electronic communications - email, text

- In-person communications - face-to-face, webinar, phone

- Media venues - video, radio

- Library job advertisements \& volunteer opportunities

- Conference presentations

- Information tables 
- Annual reports

- Accreditations

- Budget documents ${ }^{14}$

- Search Engine Optimization (SEO) $)^{15}$ and Semantic Web Identity (SWI $)^{16}$

- Social Media Optimization (SMO $)^{17} \&$ Accessible Social Media ${ }^{18}$

Then, for each of these promotional venue areas, establish:

- Responsible party(ies) \& roles

- Content

- Frequency of update - one time, daily, monthly, annually, as-needed

- Target audience(s)

- Tone \& voice

- Personality

- Accessibility (ADA)

- Key messages for that platform

- Assessment/Evaluation Approaches - User Experience (UX), etc.

\section{Promotional Strategies and Actions}

For each of the key messages, you will want to identify the communication format(s) used and the strategies employed. For instance, if you have the goal to promote the library as a warm, welcoming place, you could identify social media as the communication format used and take pictures of the library and screenshots of digital collections to post on social media platforms.

\section{Workflows \& Style Guide}

To make it easier for members of your organization to identify where they want to communicate and what they communicate, a style guide can be a useful part of your communication plan. It is likely your parent organization will already have such a guide that you would want to consult in conjunction with creating this section of your plan. For each of the areas, include any relevant procedures, permissions needed, and persons or offices to contact. Some possible areas to put in your style guide include:

- Style guide including use of logos, colors, fonts, capitalization, naming (such as how to refer to the library and its departments)

- Web Content Lifecycle

- Web Help \& Communications

- Library Promotion Locations \& Procedures

- Event Promotions \& Media List (external from Library)

- Locations for Hanging Posters

- Calendar of Key Events Relevant to the Library

- Condensed Communications Guide for Library Staff

\section{Other Plans and Policies}

Your library may also have other plans such as a disaster plan or an instruction services plan. These do not need to be repeated or duplicated in your communication plan, but you can add a section to your communication plan which reminds people maintaining other plans to 
include the main categories used in the communication plan, in addition to whatever other categories are needed for that specific plan. Also, policies would not need all of these categories as they are intended to set broad boundaries and scope around a function, but they can still embrace language from the S\&P.

\section{Socializing the Communication Plan}

Objective: Create a common understanding of the library's S\&P by its employees, frame library efforts around the S\&P, and have commonly understood approaches to communicating about these efforts.

\section{Understanding How Communication Fits into the Daily Work of the Organization}

The adoption of the communication plan by your organization will help integrate the other parts of the S\&P into the daily work of the library. While you may have a few individuals lead the process of constructing the communication plan, engaging as many other people in your organization into that process will help them feel invested in the plan, will raise immediate awareness about the plan, and will provide more perspectives and ideas to make the plan more adaptable to a variety of working styles and situations. Also, if you return to the values statement you created, you will likely find values which would encourage you to be inclusive, transparent, or participatory in your processes. Now is a good time to put those values into practice!

As a starting point, consider giving people a set of prompts to think about regarding their daily work, the parts of the S\&P, including your communication plan. By helping them actualize how the pieces of the plan would align with their daily work, you can gain perspectives of how you might construct your plan. First, consider providing a template for members of your organization to complete with some guiding options to keep their answers aligned with the strategic plan. These completed templates can then inform discussions in groups and one-onone.

\section{Prompts for Library Employee Communication Exercise}

1. Identify a specific role you perform in your work or a project on which you are currently working or on which will soon be working.

2. Who in our community (both others in the library and our broader community) does/could benefit from your work?

3. Review our values statement. What values are reflected in this work?

4. Review our mission statement and vision statement. How does this work help the library meet its mission and achieve its vision?

5. Identify places used or potentially used to communicate about this work. Keep in mind the intended audience in those communication venues.

6. Is this regular, ongoing communication or is a targeted campaign (i.e. intense communication that has a start and end)?

7. What would be the key messages for this communication? Do you have any stories that illustrate these key messages?

8. What would be the tone, tenor, personality of this communication?

9. How would you know if you were successful in this communication? How would you measure "communication success"?

10. Where/how/who do you need help to carry out this communication? What resources such as people, funds, platforms, education would be beneficial? 


\section{Involving Others in the Creation of the Communication Plan}

With the template questions shared with members of your organization, consider using some of these engagement strategies to involve others in the creation and use of the communication plan, as inspired by the Alberta Open Educational Resources Champion's Toolkit. ${ }^{19}$

Formal presentation: A meeting with the administrative team of your library will allow this group to explore the benefits of a communication plan and to become champions for its adoption in the rest of the organization. It is key to get this group on board for enacting the plan.

Informal presentation: Other members of your organization may be interested in learning more about the communication plan. Having a few stories of how using the communication plan benefits the library and the community can drive home this message.

Special interest group: Some of your key stakeholders may be outside the administrative team. Consider who in your organization is invested in outreach, user experience, good customer service, using a consistent, controlled vocabulary, etc. Get these people into the room to exchange ideas of where key communication points are for the organization and what messaging is best suited for these points.

Facilitated group discussion: Organizing a facilitated group discussion allows people to make input and to hear the perspectives of others. These sessions can build understanding that the plan had input beyond the coordinators of the process.

Individual discussions: Informal conversations with members of your organization may be less threatening to some people and may provide insights into the real daily challenges with communication of the organization. Make a point to ask for the ideas of those who do not speak up in group settings.

Modelling/exemplars: The communication plan will be a new concept to many in your organization. To help them gain context and understanding about what would come about from enacting a plan, give a few examples of the results of enacting the plan, such as support from administration for an increase to the library's budget, increased student use of library services, and more collaboration between the library and other parts of the parent organization.

Collaboration: Other parts of your parent organization may have expertise in some areas of your communication plan. Consider checking in with your public relations office, your graphic design associates, and others to make sure your plan is coordinated with these groups.

\section{Keeping the Plan Alive}

Your communication plan should be introduced to new employees as they enter the organization and should remain an active part of their daily work throughout their tenure. This active nature of the plan will ensure consistent communication from the library and will keep the S\&P as an integral part of daily work. Remember that each of the parts of your strategic plan has frequency goals for collecting information which will also return people to the communication plan for how that progress is being communicated.

While some of your employees will have been in the organization when creating your S\&P, including the communication plan, you will have new employees entering the organization 
after its creation. To emphasize the importance of the S\&P, it is prudent to include an orientation to the S\&P during employee orientation. Ideally, this introduction will include how that person's work fits into the S\&P and some potential scenarios in which that person might use the communication plan.

Revisiting the communication plan and the other parts of the S\&P at meetings, in annual performance reviews, and in setting annual goals for individuals and teams can reinforce the importance of the S\&P to the daily work of the organization.

\section{Further Discussion}

The topics discussed here emphasize the importance of having a communication plan which is informed by the statements and plans created by your organization. Further articles in this brief series will cover the details of forming a budget communication plan and a social media optimization and communication plan which align with your overall communication plan. These plans go beyond traditional communications and incorporate your S\&P language into other areas which reflect the work of the library. These articles complement other resources I listed in the "Communication Venues" portion of "Creating the Communication Plan" section of this article. If there are additional areas you would like me to cover in future articles, please contact me at email (doralyn@montana.edu) or twitter (@doralyn). Happy communicating!

\section{Bibliography}

Alberta Open Educational Resources. “ABOER Champion's Toolkit v2.0.” Google Docs. 2018. https://docs.google.com/document/d/1FytdhaXwvGVHKv2ZB4HtphTNYCPsfl8m68Q xw3CdQ/edit?usp=sharing\&usp=embed fac ebook.

American Library Association. "Core Values of Librarianship." July 26, 2006. http://www.ala.org/advocacy/intfreedom/corevalues

Arlitsch, Kenning. "Semantic Web Identity of Academic Libraries." Journal of Library Administration 57, no. 3 (April 3, 2017): 346-58. https://doi.org/10.1080/01930826.2017.1288970.

Arlitsch, Kenning, Patrick OBrien, and Brian Rossmann. "Managing Search Engine Optimization: An Introduction for Library Administrators." Journal of Library Administration 53, no. 2-3 (February 1, 2013): 177-88. https://doi.org/10.1080/01930826.2013.853499.

Association of Specialized and Cooperative Library Agencies. "Tools \& Resources - ASCLA Direct." 2018. https://www.ascladirect.org/resources/.

Cervone, H. Frank. "Improving Strategic Planning by Adapting Agile Methods to the Planning Process." Journal of Library Administration 54, no. 2 (February 17, 2014): 155-68. https://doi.org/10.1080/01930826.2014.903371.

Dole, Wanda V., Katherine Dabbour, and Katherine Kott. "Dialogic Approaches to Strategic 
Planning in Academic Libraries: An Appreciative Inquiry Case Study at Oviatt Library." Journal of Library Administration 57, no. 4 (May 19, 2017): 468-80.

https://doi.org/10.1080/01930826.2017.1300499.

International Federation of Library Associations and Institutions. "IFLA -- More about IFLA." 2018. https://www.ifla.org/about/more.

Kuchi, Triveni. "Constant Change and the Strategic Role of Communication: A Selective Annotated Bibliography." Library Management; Bradford 27, no. 4/5 (2006): 218-35. https://doi.org/10.1108/01435120610668160.

Lucas-Alfieri, Debra. Marketing the 21st Century Library: The Time Is Now. Chandos Publishing, 2015.

Miller, Steven A., R.W. Hildreth, and LaShonda M. Stewart. "The Modes of Participation: A Revised Frame for Identifying and Analyzing Participation." Administration \& Society, (July 24, 2017): 1-28. https://doi.org/10.1177/0095399717718325.

Nutefall, Jennifer. "How an Outside Facilitator Helped Us Create a Better Strategic Plan." Library Leadership \& Management 29, no. 3 (March 25, 2015). https://journals.tdl.org/llm/index.php/llm/article/view/7112.

Rossmann, Doralyn, and Kenning Arlitsch. "From Acquisitions to Access: The Changing Nature of Library Budgeting." Journal of Library Administration 55, no. 5 (July 4, 2015): 394404. https://doi.org/10.1080/01930826.2015.1047279.

Saunders, Laura. "Academic Libraries' Strategic Plans: Top Trends and Under-Recognized Areas." The Journal of Academic Librarianship 41, no. 3 (May 1, 2015): 285-91. https://doi.org/10.1016/j.acalib.2015.03.011.

Society for Human Resource Management. "Practicing Strategic Human Resources." 2018. https://www.shrm.org/resourcesandtools/tools-andsamples/toolkits/pages/practicingstrategichumanresources.aspx..

University of Minnesota. “Accessible Social Media | Accessible U.” 2018. https://accessibility.umn.edu/tutorials/accessible-social-media.

Wayne, Richard. "The Academic Library Strategic Planning Puzzle: Putting the Pieces Together." College \& Research Libraries News 72, no. 1 (January 2011): 1215.http://crln.acrl.org/index.php/crlnews/article/view/8489/8766.

Young, Scott Woodward Hazard, and Doralyn Rossmann. "Building Library Community Through Social Media." Information Technology and Libraries 34, no. 1 (March 30, 2015): 20-37. https://doi.org/10.6017/ital.v34i1.5625. 


\section{Notes}

1 "Compass" (https://thenounproject.com/icon/645573/) by Fuat șanlı is licensed under CC BY 4.0. "Rocket" (https://thenounproject.com/icon/982014/) by Tawny Whatmore is licensed under CC BY 4.0. "Eye" (https://thenounproject.com/icon/1584877/) by Alvaro Cabrera is licensed under CC BY 4.0. "Watering" (https://thenounproject.com/icon/326760/) by Joshua Ganyon is licensed under CC BY 4.0. "Message Bubble" (https://thenounproject.com/icon/1293462/) by Maxim Basinski is licensed under CC BY 4.0. This collection, titled "The 5 Parts of the Statements and Plans" by Doralyn Rossmann, is licensed under CC BY 4.0.

${ }^{2}$ Miller, Steven A., R.W. Hildreth, and LaShonda M. Stewart. "The Modes of Participation: A Revised Frame for Identifying and Analyzing Participation." Administration \& Society, (July 24, 2017): 1-28. https://doi.org/10.1177/0095399717718325.

${ }^{3}$ Wayne, Richard. "The Academic Library Strategic Planning Puzzle: Putting the Pieces Together." College \& Research Libraries News. 2018. http://crln.acrl.org/index.php/crlnews/article/view/8489/8766.

${ }^{4}$ Nutefall, Jennifer. "How an Outside Facilitator Helped Us Create a Better Strategic Plan." Library Leadership \& Management 29, no. 3 (March 25, 2015). https://journals.tdl.org/llm/index.php/llm/article/view/7112.

${ }^{5}$ Cervone, H. Frank. "Improving Strategic Planning by Adapting Agile Methods to the Planning Process." Journal of Library Administration 54, no. 2 (February 17, 2014): 155-68. https://doi.org/10.1080/01930826.2014.903371.

${ }^{6}$ Dole, Wanda V., Katherine Dabbour, and Katherine Kott. "Dialogic Approaches to Strategic Planning in Academic Libraries: An Appreciative Inquiry Case Study at Oviatt Library." Journal of Library Administration 57, no. 4 (May 19, 2017): 468-80. https://doi.org/10.1080/01930826.2017.1300499.

7 Saunders, Laura. "Academic Libraries' Strategic Plans: Top Trends and Under-Recognized Areas." The Journal of Academic Librarianship 41, no. 3 (May 1, 2015): 285-91.

https://doi.org/10.1016/j.acalib.2015.03.011.

${ }^{8}$ Society for Human Resource Management. "Practicing Strategic Human Resources." 2018.

https://www.shrm.org/resourcesandtools/tools-and-

samples/toolkits/pages/practicingstrategichumanresources.aspx.

${ }^{9}$ American Library Association. "Core Values of Librarianship." July 26, 2006.

http://www.ala.org/advocacy/intfreedom/corevalues and International Federation of Library Associations and Institutions. "IFLA -- More about IFLA." 2018. https://www.ifla.org/about/more.

${ }^{10}$ Society for Human Resource Management. "Practicing Strategic Human Resources." 2018.

https://www.shrm.org/resourcesandtools/tools-and-

samples/toolkits/pages/practicingstrategichumanresources.aspx.

${ }^{11}$ Ibid. 
12 Lucas-Alfieri, Debra. Marketing the 21st Century Library: The Time Is Now. Chandos Publishing, 2015.

${ }^{13}$ Association of Specialized and Cooperative Library Agencies. "Tools \& Resources - ASCLA Direct." 2018. https://www.ascladirect.org/resources/.

${ }^{14}$ See Rossmann, Doralyn, and Kenning Arlitsch. "From Acquisitions to Access: The Changing Nature of Library Budgeting." Journal of Library Administration 55, no. 5 (July 4, 2015): 394-404.

https://doi.org/10.1080/01930826.2015.1047279.

15 See Arlitsch, Kenning, Patrick OBrien, and Brian Rossmann. "Managing Search Engine Optimization: An Introduction for Library Administrators." Journal of Library Administration 53, no. 2-3 (February 1, 2013): 177-88. https://doi.org/10.1080/01930826.2013.853499.

${ }^{16}$ See Arlitsch, Kenning. "Semantic Web Identity of Academic Libraries." Journal of Library Administration 57, no. 3 (April 3, 2017): 346-58. https://doi.org/10.1080/01930826.2017.1288970.

17 Young, Scott Woodward Hazard, and Doralyn Rossmann. "Building Library Community Through Social Media.” Information Technology and Libraries 34, no. 1 (March 30, 2015): 20-37. https://doi.org/10.6017/ital.v34i1.5625.

18 University of Minnesota. "Accessible Social Media | Accessible U." 2018.

https://accessibility.umn.edu/tutorials/accessible-social-media.

${ }^{19}$ Alberta Open Educational Resources. "ABOER Champion's Toolkit v2.0." Google Docs. 2018. https://docs.google.com/document/d/1FytdhaXwvGVHKv2ZB4HtphTNYCPsfl8m68Q xw3CdQ/edit?usp=sharing\&usp=embed facebook. 